\title{
Purification, Characterization and Serological Properties of a Glycolipid Antigen Reactive with a Serovar-specific Monoclonal Antibody against Leptospira interrogans serovar canicola
}

\author{
By E. ONO, ${ }^{1}$ H. TAKASE, ${ }^{1}$ M. NAIKI ${ }^{2}$ AND R. YANAGAWA ${ }^{1 *}$ \\ Department of Hygiene and Microbiology ${ }^{1}$ and Department of Biochemistry ${ }^{2}$, Faculty of \\ Veterinary Medicine, Hokkaido University, Sapporo 060, Japan
}

(Received 5 August 1986; revised 26 November 1986)

\begin{abstract}
A glycolipid antigen possessing a serovar-specific antigenic determinant of Leptospira interrogans serovar canicola was purified from a chloroform/methanol extract of the organism. The purification procedures included silicic acid column chromatography and preparative thinlayer chromatography (TLC). Antigenic activity was detected by a TLC-enzyme immunostaining technique using monoclonal antibody $\mathrm{CT} 3$, which specifically agglutinates serovar canicola and only weakly serovar sumneri but no other serovars of Leptospira. The purified glycolipid reacted with CT3 antibody, indicating that the glycolipid possessed a serovar-specific antigenic determinant. Infrared spectrum and proton nuclear magnetic resonance analyses showed that the glycolipid contained sugar and lipid moieties, which possessed amide linkages and an acetyl group. Gas-liquid chromatography-mass spectrometry analysis showed that the glycolipid contained two unknown sugars, one of which (unknown sugar II) appeared to be associated with the antigenic determinant specific for canicola. The serovar-specific antigenic determinant was destroyed by mild alkali treatment of the glycolipid. These findings suggested that the antigenic determinant was an alkali-labile moiety which may be related to the unknown sugar II.
\end{abstract}

\section{INTRODUCTION}

Determinants of serovar-specific antigen of Leptospira interrogans have not been defined. In our previous studies of serovar-specific antigenic determinant(s), the serovar-specific lipopolysaccharide antigen (TM antigen) (Shinagawa \& Yanagawa, 1972) was used. We produced several monoclonal antibodies against TM antigen of Leptospira interrogans serovar canicola and classified them into three groups by their cross-reactivities (Ono et al., 1982). These antigenic determinant groups on TM antigen of serovar canicola were different in their chemical properties. The group I determinant, which was recognized by monoclonal antibody CT3, was destroyed by mild alkali treatment with $0.1 \mathrm{M}-\mathrm{NaOH}$; however, it was quite resistant to mild acid hydrolysis with $2 \mathrm{~m}$-formic acid. On the other hand, the group II determinant, which was recognized by monoclonal antibody $\mathrm{CT} 5$, was stable to the alkali treatment, but unstable to the acid treatment. The group III determinant, which was recognized by monoclonal antibody CT6, was unstable to both treatments. An antigenic oligosaccharide fraction containing the group I determinant, with an $M_{\mathrm{r}}$ of 1500-1800, was isolated from the TM antigen of serovar canicola by formic acid and successive sulphuric acid hydrolyses (Ono et al., 1984). The fraction, however, was still a mixture of two oligosaccharides, and the small yield of the oligosaccharide fraction made it difficult to separate the two oligosaccharides.

Leptospires have a high lipid content (18-26\%) (Johnson et al., 1970). The antigenic activity of glycolipids of leptospires has not been investigated. However, immunogenic glycolipids of Mycobacterium have been studied and have been found to be species- or type-specific antigens (Brennan \& Goren, 1979; Brennan et al., 1981; Hunter et al., 1982, 1985). Therefore, we 
examined whether or not glycolipids from Leptospira interrogans serovar canicola shared the same antigenic determinants as the $\mathrm{TM}$ antigen by using monoclonal antibodies against the TM antigen. A glycolipid containing a serovar-specific antigenic determinant (the group I determinant) was found. The purification, characterization and serological properties of this glycolipid antigen are described in the present paper.

\section{METHODS}

Strains and medium. Leptospira interrogans serovar canicola strain Hond Utrecht IV, provided by the Leptospirosis Reference Laboratory, National Institute of Health, Tokyo, Japan, was grown in protein-free medium (Bey \& Johnson, 1978 ) at $30^{\circ} \mathrm{C}$ for one week and harvested by continuous-flow centrifugation at $12000 \mathrm{~g}$. Twelve other reference strains belonging to the Canicola serogroup and nine other reference strains belonging to different serogroups of Leptospira interrogans, Leptospira biflexa serovar patoc and Leptonema illini were examined with monoclonal antibody CT3. Among them, Leptospira interrogans serovars bafani Bafani, benjamini Benjamin, galtoni LT 1014, jonsis Jones, kamituga Kamituga, malaya $\mathrm{H6}$, schueffneri Vleermuis $90 \mathrm{C}$ and Leptonema illini were from the Center for Disease Control, Atlanta, Ga., USA; Leptospira interrogans serovars bindjei Bindjei, broomi Patane and sumneri Sumner were from the Istituto Superiore di Sanita, Rome, Italy; serovars kuwait 136/2/2 and portland-vere LT63-69 were from the Royal Tropical Institute, Amsterdam, The Netherlands; serovar perameles Bandicoot 343 was from the Walter Reed Army Medical Center, Washington, DC, USA; serovars australis Ballico, autumnalis Akiyami A, grippotyphosa Moskva V, hardjo Hardjoprajitno, hebdomadis Hebdomadis, icterohaemorrhagiae RGA, pomona Pomona and pyrogenes Salinem, and Leptospira biflexa serovar patoc Patoc 1 were provided by the National Institute of Health, Tokyo, Japan. These strains, except for serovar canicola, were grown in $0.2 \%$ (w/v) tryptose phosphate broth containing $10 \%(\mathrm{v} / \mathrm{v})$ normal rabbit serum (Cox, 1955).

Purification of the glycolipid antigen from Leptospira interrogans serovar canicola. Lyophilized leptospiral cells $(30 \mathrm{~g}$ dry weight), harvested from approximately 7001 leptospiral culture, were extracted with 3.31 chloroform/methanol $(2: 1, \mathrm{v} / \mathrm{v})$ for $24 \mathrm{~h}$ at room temperature, and the residue was reextracted with the same volume of chloroform/methanol $(1: 1, \mathrm{v} / \mathrm{v})$ overnight at room temperature. The pooled extract was evaporated to $20 \mathrm{ml}$ and then 9 vols acetone were added. Acetone-insoluble lipids $(9 \mathrm{~g})$ were obtained from the total lipid extract. These acetone-insoluble lipids $(1 \mathrm{~g})$, dissolved in chloroform/methanol $(3: 1, \mathrm{v} / \mathrm{v})$, were loaded on a $3 \times 28 \mathrm{~cm}$ column of silicic acid (Iatrobeads, Iatron Chemical Co., Tokyo, Japan) and eluted successively with two bed vols of each of the following solvents; chloroform/methanol $(3: 1, \mathrm{v} / \mathrm{v})$, chloroform/methanol $(1: 1, \mathrm{v} / \mathrm{v})$, chloroform/methanol $(1: 3, \mathrm{v} / \mathrm{v})$ and methanol. Methanol-eluted compounds $(1 \cdot 1 \mathrm{~g})$ were obtained from $9 \mathrm{~g}$ of the acetone-insoluble lipids. The methanol-eluted compounds were separated by preparative thin-layer chromatography (TLC) using Silica gel 60 glass plates $(20 \times 20 \mathrm{~cm}$ ) with a layer $2 \mathrm{~mm}$ or $0.5 \mathrm{~mm}$ thick (Merck) and a solvent system of chloroform/methanol/water $(50: 40: 10$, by vol.) for development. Separated glycolipids identified with respect to $R_{F}$ value and by staining with anthrone/ $\mathrm{H}_{2} \mathrm{SO}_{4}$ reagent were visualized on identical plates with $\mathrm{I}_{2}$ vapour. Each separated glycolipid visualized with $I_{2}$ vapour was scraped off and extracted from the silica gel with $1 \mathrm{ml}$ chloroform/methanol $(1: 3, \mathrm{v} / \mathrm{v})$ and repeatedly with methanol.

Monoclonal antibodies and antisera. Monoclonal antibody CT3, which was previously prepared against serovar canicola TM antigen (Ono et al., 1982), was used. Before use, the specificity of the CT3 antibody was re-examined by the microscopic agglutination test against 13 serovars belonging to the Canicola serogroup, nine serovars belonging to different serogroups of Leptospira interrogans, one serovar of Leptospira biflexa and Leptonema illini. The agglutination titre of the mouse ascitic fluid form of CT3 against serovar canicola was $1: 2560$ and against serovar sumneri, $1: 320$; the CT3 antibody did not agglutinate the remaining 11 serovars of the Canicola serogroup, nor Leptospira interrogans serovars australis, autumnalis, grippotyphosa, hardjo, hebdomadis, icterohaemorrhagiae, perameles, pomona and pyrogenes, Leptospira biflexa serovar patoc and Leptonema illini at a dilution of 1 in 40 .

The reactivity of monoclonal antibody CT3 was different from that previously reported (Ono et al., 1982); CT3 antibody agglutinated serovars canicola and broomi but not serovar sumneri in the previous study, while it agglutinated serovars canicola and sumneri but not serovar broomi in the present study. The different reactivities were due to the different origins of the reference strains: serovars broomi and sumneri, which had been obtained from the Center for Disease Control, Atlanta, USA (Ono et al., 1982), were replaced by those provided by the Istituto Superiore di Sanita, Rome, Italy. This was done because serovars broomi and sumneri used in the previous study did not possess major antigens which were reported by Dikken \& Kmety (1978).

Also, monoclonal antibody CT5 was previously prepared against the same serovar canicola TM antigen (Ono $e t$ al., 1982). The agglutination titre of the mouse ascitic fluid form of CT5 against serovar canicola was $1: 320$ and against serovar jonsis, $1: 160$; the CT5 antibody did not agglutinate the remaining 11 serovars of the Canicola serogroup, nor Leptospira interrogans serovars australis, autumnalis, grippotyphosa, hardjo, hebdomadis, icterohaemorrhagiae, perameles, pomona and pyrogenes, Leptospira biflexa serovar patoc and Leptonema illini at a dilution of 1 in 40 . 
An absorbed antiserum specific for major antigen Ca-3 (factor serum Ca-3) was provided by Dr B. Cacciapuoti, Istituto Superiore di Sanita, Rome, Italy. It was prepared according to the method of Dikken \& Kmety (1978) and had the same reactivity pattern as reported by these authors; the serum agglutinated serovar canicola at the titre of $1: 480$ and serovar broomi at the titre of $1: 120$.

The polyclonal antisera used were hyper-immune rabbit antisera against whole cells of serovars canicola, bafani, benjamini, galtoni, jonsis, kamituga, malaya and schueffneri of the Canicola serogroup, australis of the Australis serogroup, autumnalis of the Autumnalis serogroup, grippotyphosa of the Grippotyphosa serogroup, hardjo of the Sejroe serogroup, hebdomadis of the Hebdomadis serogroup, icterohaemorrhagiae of the Icterohaemorrhagiae serogroup, perameles of the Mini serogroup, pomona of the Pomona serogroup, pyrogenes of the Pyrogenes serogroup, Leptospira biflexa serovar patoc and Leptonema illini, prepared as described previously (Yanagawa et al., 1974). Antisera against serovars bindjei, broomi and sumneri of the Canicola serogroup were gifts from Dr B. Cacciapuoti, Istituto Superiore di Sanita, Rome, Italy.

TLC-enzyme immunostaining. Enzyme immunostaining of glycolipids separated on a TLC plate was done by the method of Higashi et al. (1984). Briefly, $10 \mu \mathrm{g}$ of the intact, the alkali-treated or the acid-treated glycolipid antigen, or of the acetone-insoluble lipids was applied to each lane of a Polygram Sil G TLC plate (Macherey-Nagel, West Germany) and chromatographed as shown in each figure. When completely dry, the plate was dipped in $0.01 \mathrm{M}$-sodium phosphate buffer (pH 7.0) containing $0.15 \mathrm{M}-\mathrm{NaCl}, 1 \%(\mathrm{w} / \mathrm{v})$ egg albumin and $1 \%(\mathrm{w} / \mathrm{v})$ polyvinylpyrrolidone. The plates were then cut into separate lanes, and each lane was immunostained with a different antibody solution. Monoclonal antibody CT3 or CT5 (mouse ascitic fluid form) was used at a dilution of $1: 100$, factor serum Ca-3 was used at a dilution of $1: 6000$ and other polyclonal antisera were used at a dilution of $1: 100$. As a second antibody, peroxidase-conjugated goat anti-mouse or anti-rabbit IgG (Bio-Rad) was used at a dilution of $1: 1000$. As a substrate for the peroxidase, 4-chloro-1-naphthol/hydrogen peroxide solution prepared according to the method of Hawkes et al. (1982) was used.

Mild alkali treatment of the glycolipid antigen. This was done by dissolving a sample of the glycolipid antigen in methanolic $0.1 \mathrm{M}-\mathrm{NaOH}$ at a concentration of $100 \mu \mathrm{g} \mathrm{ml}^{-1}$ and keeping it at room temperature for $24 \mathrm{~h}$. After neutralization with Dowex $50 \mathrm{~W}-\mathrm{X} 8\left[\mathrm{H}^{+}\right.$form], the solution was concentrated by evaporation to a concentration of $1 \mathrm{mg} \mathrm{ml}^{-1}$.

Mild acid hydrolysis of the glycolipid antigen. This was done by dissolving a sample of the glycolipid antigen in $2 \mathrm{M}$-formic acid at a concentration of $100 \mu \mathrm{g} \mathrm{ml} \mathrm{m}^{-1}$ and heating at $100^{\circ} \mathrm{C}$ for $30 \mathrm{~min}$. The acid was removed by evaporation under vacuum.

Isolation of the antigenic oligosaccharide fraction from serovar canicola TM antigen. Serovar-specific main (TM) antigen was extracted and purified from Leptospira interrogans serovar canicola strain Hond Utrecht IV as previously described (Shinagawa \& Yanagawa, 1972). The antigenic oligosaccharide fraction containing the group I determinant was isolated from the TM antigen as described by Ono et al. (1984).

Chemical and physico-chemical analyses. The infrared spectrum was recorded for a $200 \mathrm{mg} \mathrm{KBr}$ tablet containing $200 \mu \mathrm{g}$ of a sample with an A-102 infrared spectrophotometer (Japan Spectroscopic Co.).

Proton nuclear magnetic resonance (proton-NMR) of a sample was recorded with a $500 \mathrm{MHz}$ JEOL FX-500 spectrometer at a concentration of $4 \mathrm{mg} \mathrm{ml}^{-1}$ in DMSO-d $\mathrm{d}_{6}$ at $60^{\circ} \mathrm{C}$.

The neutral sugar and fatty acid compositions of the intact and alkali-treated glycolipid antigen and of the antigenic oligosaccharide fraction of TM antigen were determined by gas-liquid chromatography-mass spectrometry (GLC-MS) as described previously (Naiki et al., 1975). A sample (100 $\mu \mathrm{g})$ was hydrolysed with $5 \%$ $(\mathrm{w} / \mathrm{v}) \mathrm{HCl} /$ methanol at $80^{\circ} \mathrm{C}$ for $24 \mathrm{~h}$. After the fatty acid methyl esters had been extracted with hexane, the neutral sugar components obtained from the methanol layer were trimethylsilylated and analysed in a QP-1000 GLC-MS apparatus (Shimadzu Seisakusho). GLC-MS was done through a glass column $(4 \times 2000 \mathrm{~mm})$ packed with $2 \% \mathrm{OV}-1$ on Chromosorb W (60/80 mesh) by gradually increasing the temperature from 140 to $240{ }^{\circ} \mathrm{C}$ at a rate of $2{ }^{\circ} \mathrm{C} \mathrm{min}-1$. The fatty acid methyl esters were analysed on the same glass column at $170{ }^{\circ} \mathrm{C}$.

Peak search for the pertrimethylsilylated unknown sugar II in a standard mass-spectral library of NBS/NIH/EPA (Heller \& Milne, 1978) was kindly conducted by Shimadzu Seisakusho, Kyoto, Japan.

\section{RESULTS}

\section{Purification of the glycolipid antigen}

An acetone-insoluble lipid fraction of serovar canicola was chromatographed on a TLC plate and immunostäined with anti-canicóla monocional antibody $\mathrm{CT}^{\top} 3$. 7 wo antigenic glycólıpids with $R_{F}$ values of 0.17 and 0.35 were detected (Fig. 1). The slower-moving glycolipid was isolated by silicic acid column chromatography and preparative TLC, the latter repeated three times. The faster-moving glycolipid could not be isolated, because the glycolipid which was extracted from the scraped silica gel separated into two spots with $R_{F}$ values of 0.17 and 0.35 by TLC.

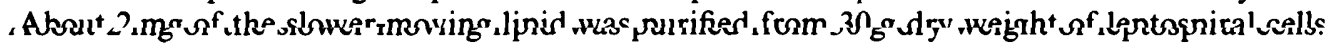




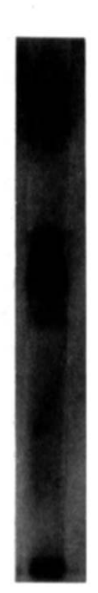

1

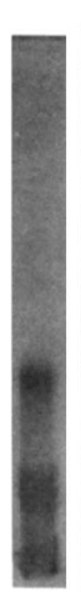

2

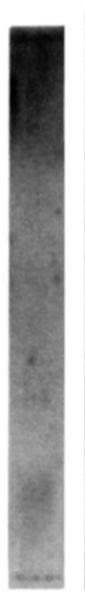

3

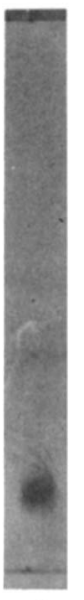

4

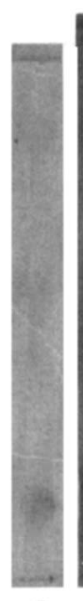

5

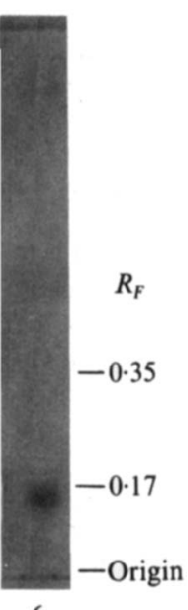

Fig. 1. Thin-layer chromatograms of acetone-insoluble lipids and the purified glycolipid antigen of Leptospira interrogans serovar canicola. Lanes 1 and 2, acetone-insoluble lipids; lanes 3-6, purified glycolipid antigen. The glycolipids in lanes 1 and 3 were visualized with anthrone $/ \mathrm{H}_{2} \mathrm{SO}_{4}$ reagent and the other lanes were immunostained with monoclonal antibody CT3 (lanes 2 and 4), monoclonal antibody CT5 (lane 5) and factor serum Ca-3 (lane 6) by TLC-enzyme immunostaining. The chromatograms were developed with chloroform/methanol/water $(50: 40: 10$, by vol.).
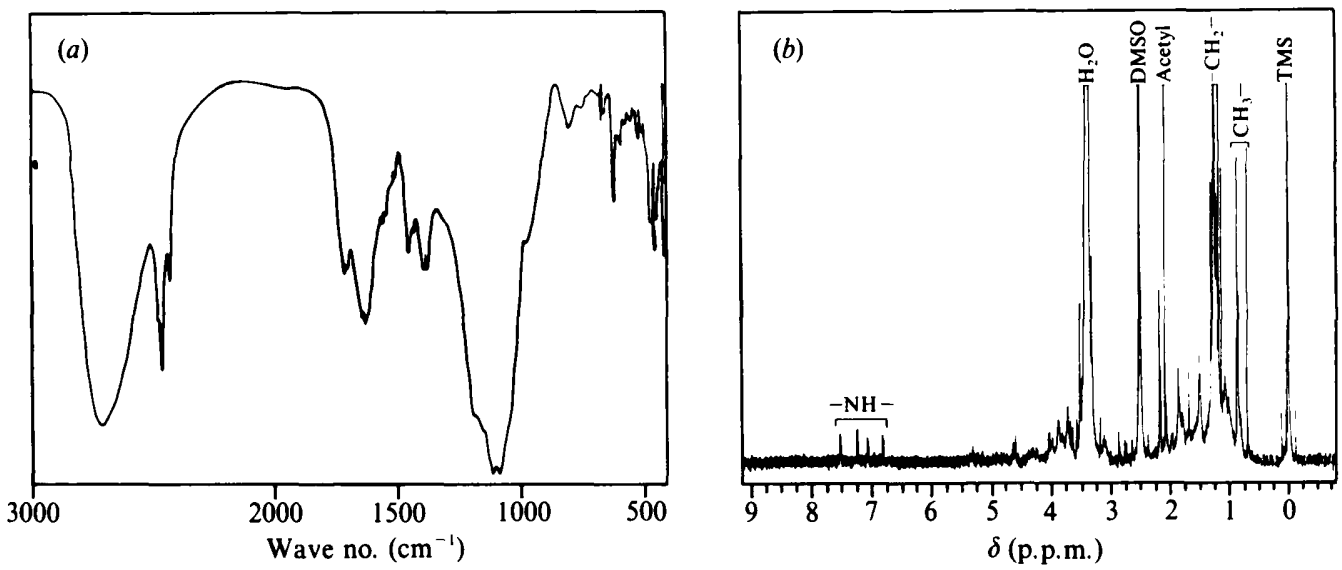

Fig. 2. Spectrometry of the purified glycolipid. (a) Infrared spectrum of the purified glycolipid in a $\mathrm{KBr}$ tablet. (b) $500 \mathrm{MHz}$ proton-NMR spectrum of the purified glycolipid in DMSO-d $\mathrm{d}_{6}$. TMS, trimethylsilane.

The purified glycolipid migrated as a single spot on the TLC plate, which was visualized by anthrone $/ \mathrm{H}_{2} \mathrm{SO}_{4}$ reagent as well as by immunostaining with monoclonal antibody CT3 or monoclonal antibody CT5 (Fig. 1). To examine whether or not the glycolipid contained a major antigen (Ca-3) of serovar canicola, which was found by Dikken \& Kmety (1978), the reactivity of the glycolipid with factor serum Ca-3 was examined by TLC-enzyme immunostaining. The glycolipid was stained by this factor serum (Fig. 1).

\section{Chemical properties of the glycolipid antigen}

The infrared spectrum of the purified glycolipid is shown in Fig. 2(a). The strong absorption bands at 3400 and $1120 \mathrm{~cm}^{-1}$ wave numbers showed the presence of many hydroxyl groups derived from carbohydrate moieties. The methylene absorptions observed at 2900 and 


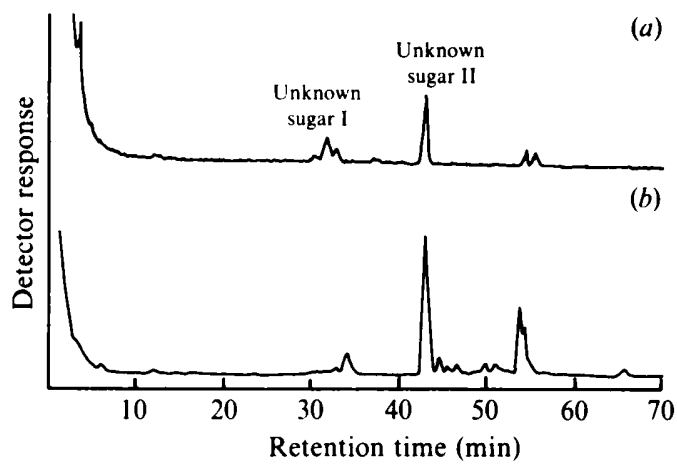

Fig. 3. GLC of the trimethylsilylated glycosides prepared from methanolysates of the purified glycolipid $(a)$ and an antigenic oligosaccharide fraction derived from TM antigen (b).

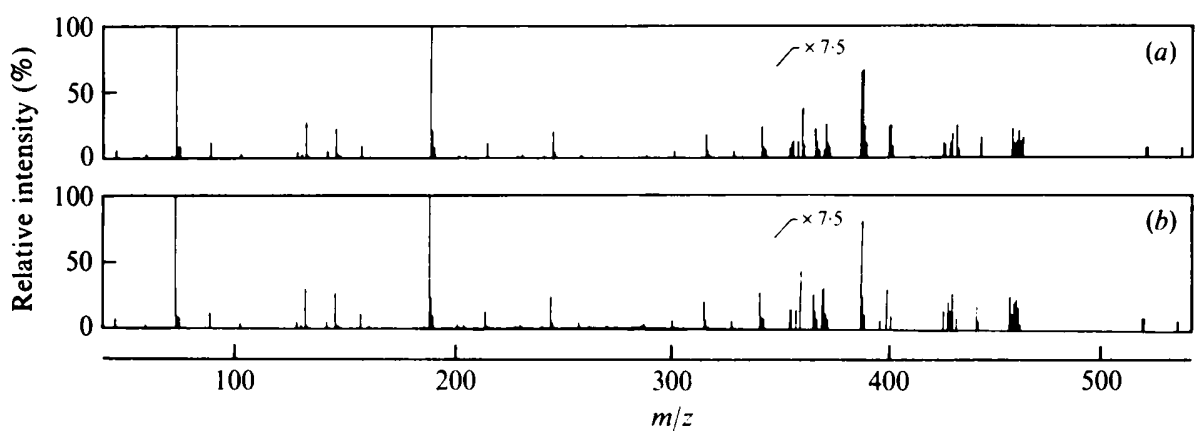

Fig. 4. Mass spectra of the trimethylsilylated unknown sugar II derived from the purified glycolipid (a) and from the antigenic oligosaccharide fraction of TM antigen $(b)$.

$1450 \mathrm{~cm}^{-1}$ indicated the presence of lipid moieties. Slight absorptions at 1650 and $800 \mathrm{~cm}^{-1}$ indicated the presence of an amide linkage and an $\alpha$-configuration of the terminal sugar moiety, respectively.

A high resolution proton-NMR spectrum of the purified glycolipid is shown in Fig. 2(b). The spectrum showed signals in the high field region which were attributable to the methyl and methylene functions of fatty acyl groups, and an acetyl group (2.09 p.p.m.); in the low field region, the signals were attributable to amide protons.

The neutral sugar composition of the purified glycolipid was analysed by GLC-MS. The major components of the glycolipid antigen were unknown sugars I and II (Fig. $3 a$ ). The molar ratio of the unknown sugar I to the unknown sugar II was approximately $1: 1$. From their retention times and the mass spectrum (Fig. $4 a$ ), the unknown sugars appeared to be different from any of the neutral sugars which have been detected in Leptospira, such as rhamnose, fucose, ribose, arabinose, xylose, 4-O-methylmannose, mannose, galactose or glucose (Yanagihara et al., 1984). The mass spectrum was not identical to any of the standard mass spectra of NBS/NIH/EPA data banks.

The neutral sugar composition of an antigenic oligosaccharide fraction containing the group I determinant of serovar canicola TM antigen (Ono et al., 1984) was also analysed for comparison. The unknown sugar II was detected as a major component (Fig. 3b). The unknown sugars II detected in the glycolipid and in the oligosaccharide fractions of TM antigen were confirmed to be identical by their retention times (Fig. $3 a, b$ ) and by mass spectra (Fig. $4 a, b$ ).

The fatty acid composition of the glycolipid antigen was analysed by GLC-MS. The glycolipid antigen contained stearic acid and myristic acid in the molar ratio $7: 3$. 
(a)

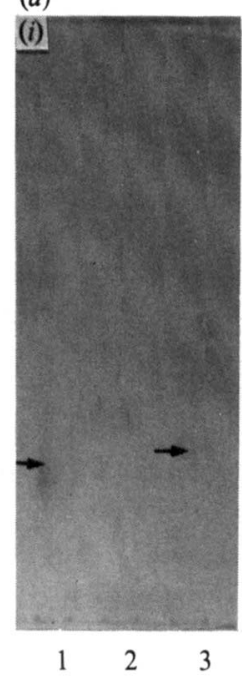

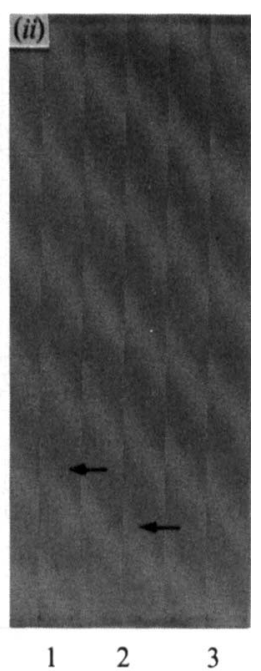

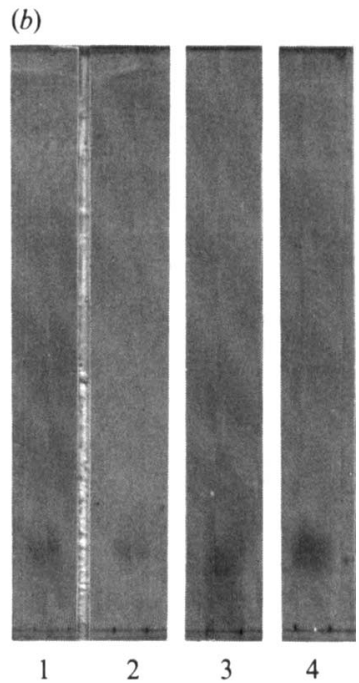

Fig. 5. Effect of mild alkali treatment or mild acid hydrolysis on reactivity of the purified glycolipid with monoclonal antibodies $(a)$ and its cross-reactivity with polyclonal antisera against leptospiral serovars $(b)$. (a) Lanes 1, intact glycolipid; lanes 2, alkali-treated glycolipid; lanes 3, acid-hydrolysed glycolipid. Small arrows point to areas of reactivity. The TLC plates were immunostained with monoclonal antibodies CT3 (i) and CT5 (ii). (b) Lanes $1-4$, purified glycolipid antigen. The TLC plates were immunostained with antisera against serovars canicola (1), broomi (2), malaya (3) and sumneri (4). TLC and TLC-enzyme immunostaining were done as shown in Fig. 1.

\section{Effect of mild alkali treatment or mild acid hydrolysis of the glycolipid antigen on its reactivity with monoclonal antibodies CT3 and CT5}

The glycolipid antigen possessed an alkali-stable antigenic determinant recognized by monoclonal antibody $\mathrm{CT} 5$, in addition to the serovar-specific antigenic determinant recognized by monoclonal antibody CT3. Mild alkali treatment of the glycolipid destroyed the reactivity with the CT3 antibody (Fig. 5a-i) and brought about a decrease in mobility in TLC (Fig. 5a). In contrast, both the intact and the alkali-treated glycolipid were immunostained with the CT5 antibody (Fig. $5 a$-ii).

Conversely, mild acid hydrolysis of the glycolipid destroyed the reactivity with the CT5 antibody (Fig. 5a-ii) and brought about a slight increase in mobility in TLC (Fig. 5a). The serovar-specific antigenic determinant to the CT3 antibody, however, was not destroyed by the hydrolysis (Fig. 5a-i).

\section{Effect of mild alkali treatment on the chemical properties of the glycolipid antigen}

The neutral sugar and fatty acid compositions of the alkali-treated glycolipid were analysed by GLC-MS. No difference between the intact and the alkali-treated compounds was observed in the neutral sugar composition. The fatty acid composition was not changed, but the stearic acid content was decreased approximately $80 \%$ by mild alkali treatment.

\section{Cross-reactivity of the glycolipid antigen with antisera against other leptospires of the Canicola and other serogroups}

To examine whether or not the antigenic determinant(s) of the glycolipid antigen were shared with other serovars of the Canicola or other serogroups, the cross-reactivity of the glycolipid with antisera against other leptospires was examined by TLC-enzyme immunostaining. The glycolipid antigen was stained by antisera against serovars broomi, malaya and sumneri of the Canicola serogroup as well as with the homologous antiserum (Fig. $5 b$ ). It was also weakly stained with antisera against serovars benjamini and jonsis of the Canicola serogroup, and serovars icterohaemorrhagiae and pyrogenes of other serogroups, but was not stained with 
antisera against the remaining serovars of the Canicola serogroup, against serovars australis, autumnalis, grippotyphosa, hardjo, hebdomadis, perameles and pomona, and against Leptospira biflexa serovar patoc and Leptonema illini.

\section{DISCUSSION}

A glycolipid antigen from Leptospira interrogans serovar canicola has been shown to contain a serovar-specific antigenic determinant, which can be recognized by a serovar-specific monoclonal antibody CT3. The monoclonal antibody CT3 strongly agglutinated serovar canicola and weakly serovar sumneri but no other serovars of the Canicola serogroup. Furthermore, the glycolipid reacted with factor serum $\mathrm{Ca}-3$, which was an agglutinin-absorbed serum containing antibodies against the major antigen $\mathrm{Ca}-3$ of serovar canicola, indicating that the glycolipid contained the major antigen of serovar canicola.

The antigenic determinant recognized by the monoclonal antibody CT3 was easily destroyed by mild alkali treatment as found previously (Ono et al., 1984). A major sugar component (unknown sugar II) of both the glycolipid and the antigenic oligosaccharide fraction isolated from TM antigen may possess an alkali-labile moiety or a group such as an $O$-acetyl group. Twodimensional proton-NMR studies are now in progress to investigate this possibility.

The unknown sugar II differed from common neutral sugars which have been detected in various Leptospira (Yanagihara et al., 1984). The structure of the unknown sugar II, however, could not be defined in the present study, because the yield of the compound was extremely small. The native and its derivatives will have to be examined by high resolution proton-NMR, ${ }^{13} \mathrm{C}-\mathrm{NMR}$ and GLC-MS to elucidate the exact structure.

The glycolipid reacted with another monoclonal antibody, CT5, which recognized the group II determinant. Alkali treatment of the glycolipid, which made it more hydrophilic, destroyed its reactivity with the CT3 antibody but not with the CT5 antibody. In contrast, on mild acid hydrolysis the glycolipid lost reactivity with the CT5 antibody but not with the CT 3 antibody. These results indicate that these two antibodies recognize different moieties or parts of the carbohydrate chain(s) of the glycolipid.

The glycolipid appeared to possess other antigenic determinant(s), because factor serum Ca-3, which cross-reacted with serovar broomi, was also reactive with this antigen. Moreover, just as the CT3 antibody cross-reacted with serovar sumneri and the CT5 antibody with serovar jonsis, so polyclonal antisera against serovars sumneri, jonsis and broomi reacted with the glycolipid. The glycolipid was, however, also immunostained with antisera against serovars malaya, benjamini, icterohaemorrhagiae and pyrogenes. These facts suggest that more than three antigenic determinants may exist on the glycolipid.

Serovar-specific main (TM) antigen has been extracted from different serovars of Leptospira interrogans (Shinagawa \& Yanagawa, 1972; Kasai \& Yanagawa, 1974; Adachi \& Yanagawa, 1975, 1977, 1978; Kawaoka et al., 1979, 1982; Shimono et al., 1979; Tsuji et al., 1981 ; Ono et al., 1984). TM antigen possessed properties similar to those of the lipopolysaccharide of Gramnegative bacteria (Shinagawa \& Yanagawa, 1972). Monoclonal antibodies CT3 and CT5, used in the present study, were prepared against TM antigen of serovar canicola, and factor serum Ca3 reacted with the TM antigen in ELISA (unpublished data). These antibodies reacted with the glycolipid antigen, indicating that several common antigenic determinants exist between the glycolipid and TM antigen. TLC analysis of both antigens showed that the glycolipid differed in mobility from TM antigen; TM antigen did not migrate from the origin on the TLC plate (data not shown). A haptenic compound for structural elucidation has not yet been purified from hydrolysate of TM antigen, despite numerous studies (Kasai \& Yanagawa, 1974; Adachi \& Yanagawa, 1975, 1978; Tsuji et al., 1981; Kawaoka et al., 1982; Ono et al., 1984). As the present glycolipid antigen could be purified without much difficulty, it may prove to be a superior material for elucidating the structure of leptospiral antigenic determinants.

The present study is the first report describing the purification and characterization of a leptospiral glycolipid antigen. Studies on the structures of the unknown sugar II and of the glycolipid antigen are now in progress. 
We are grateful to Dr B. Cacciapuoti, Istituto Superiore di Sanita, Rome, Italy, for providing factor serum and antisera. This work was supported by Grants-in-Aid for Scientific Research no. 58440012, no. 59760208 and no. 60440020 from the Ministry of Education, Science and Culture of Japan.

\section{REFERENCES}

Adachi, Y. \& Yanagawa, R. (1975). Possible role of protein(s) as antigenic determinant of the typespecific main antigen of Leptospira kremastos strain Kyoto. Infection and Immunity 11, 1325-1331.

ADACHI, Y. \& YANAGAWA, R. (1977). Inhibition of leptospiral agglutination by the type-specific main antigen of leptospiras. Infection and Immunity 17, 466-467.

ADACHI, Y. \& YANAGAWA, R. (1978). Nature of antigenic determinant of serovar-specific antigen of Leptospira interrogans serovar hebdomadis. Microbiology and Immunology 22, 523-533.

BEY, R. F. \& Johnson, R. C. (1978). Protein-free and low-protein media for the cultivation of Leptospira. Infection and Immunity 19, 562-569.

Brennan, P. J. \& Goren, M. B. (1979). Structural studies on the type-specific antigens and lipids of the Mycobacterium avium-Mycobacterium intracellulareMycohacterium scrofulaceum serocomplex. Journal of Biological Chemistry 254, 4205-4211.

Brennan, P. J., Aspinall, G. O. \& Shin, J. E. (1981). Structure of the specific oligosaccharides from the glycopeptidolipid antigen of serovars in the $\mathrm{Myco}$ bacterium avium-Mycobacterium intracellulareMycobacterium scrofulaceum complex. Journal of Biological Chemistry 256, 68176822.

Cox, C. D. (1955). Hemolysis of sheep erythrocytes sensitized with leptospiral extracts. Proceedings of the Society for Experimental Biology and Medicine 90 , 610-615.

DikKeN, H. \& KMETY, E. (1978). Serological typing methods of leptospires. Methods in Microbiology 11, 260-308.

Hawkes, R., Niday, E. \& Gordon, J. (1982). A dotimmunobinding assay for monoclonal and other antibodies. Analytical Biochemistry 119, 142-147.

Heller, S. R. \& Milne, G. W. A. (1978). EPA/NIH Mass Spectral Data Base. Washington: US Government Printing Office.

Higashi, H., Fukui, Y., Ueda, S., Kato, S., Hirabayashi, Y., Matsumoto, M. \& NaIKı, M. (1984). Sensitive enzyme-immunostaining and densitometric determination on thin-layer chromatography of $N$-glycolylneuraminic acid-containing glycosphingolipids, Hanganutziu-Deicher antigens. Journal of Biochemistry 95, 1517-1520.

Hunter, S. W., fujiwara, T. \& Brennan, P. J. (1982). Structure and antigenicity of the major specific glycolipid antigen of Mycobacterium leprae. Journal of Biological Chemistry 257, 15072-15078.

Hunter, S. W., Jardine, I., Yanagihara, D. L. \& Brennan, P. J. (1985). Trehalose-containing lipooligosaccharides from mycobacteria: structure of the oligosaccharide segments and recognition of a unique $N$-acylkanosamine-containing epitope. Biochemistry 24, 2798-2805.
Johnson, R. C., Livermore, P. B., Walby, J. K. \& JENKIN, H. M. (1970). Lipids of parasitic and saprophytic leptospires. Infection and Immunity 2, 286-291.

Kasal, N. \& Yanagawa, R. (1974). Studies on the antigenic determinant group of the type-specific antigen of Leptospira canicola. Zentralblatt für Bakteriologie, Parasitenkunde, Infektionskrankheiten und Hygiene (Abteilung I, Originale A) 228, 533-541.

KaWaOka, Y., NaIKI, M. \& Yanagawa, R. (1979). Radioimmunoassay system using a serovar-specific lipopolysaccharide antigen of Leptospira. Journal of Clinical Microbiology 10, 313-316.

Kawaoka, Y., NaIK1, M. \& Yanagawa, R. (1982). Isolation of antigen-active components from leptospiral serovar-specific lipopolysaccharide antigen by mild acid hydrolysis. Japanese Journal of Veterinary Science 44, 473-478.

NaIKI, M., Fong, J., Ledeen, R. \& Marcus, D. M. (1975). The structure of the human erythrocyte blood group $\mathrm{P}_{1}$ glycosphingolipid. Biochemistry 14, 48314836.

Ono, E., Naiki, M. \& Yanagawa, R. (1982). Production and characterization of monoclonal antibodies to lipopolysaccharide antigen of Leptospira interrogans serovar kremastos and canicola. Zentralblatt für Bakteriologie, Parasitenkunde, Infektionskrankheiten und Hygiene (Abteilung I, Originale A) 252, 414-424.

Ono, E., NaIKI, M. \& Yanagawa, R. (1984). Isolation of an antigenic oligosaccharide fraction from Leptospira interrogans serovar canicola with a monoclonal antibody. Journal of General Microbiology 130, 14291435.

Shimono, E., Sugiyama, K. \& Yanagawa, R. (1979). Specificity of serovar-specific main antigen of leptospiras shown by the inhibition of leptospiral microscopic agglutination. Japanese Journal of Veterinary Science 41, 623-628.

Shinagawa, M. \& Yanagawa, R. (1972). Isolation and characterization of a leptospiral type-specific antigen. Infection and Immunity 5, 12-19.

Tsuji, M., KawaOKa, Y., NaIKI, M. \& Yanagawa, R. (1981). Isolation of antigenically active components from leptospiral serovar-specific lipopolysaccharide antigen by alkaline treatment. Microbiology and Immunology 25, 949-957.

Yanagawa, R., Shinagawa, M. \& Takashima, I. (1974). Serological studies of leptospiras by immunodiffusion. Zentralblatt für Bakteriologie, Parasitenkunde, Infektionskrankheiten und Hygiene (Abteilung I, Originale A) 228, 369-377.

Yanagihara, Y., Kamisango, K., Yasuda, S., Kobayashi, S., Mifuchi, I., AzUma, I., Yamamura, Y. \& Johnson, R. C. (1984). Chemical composition of cell walls and polysaccharide fractions of spirochetes. Microbiology and Immunology 28, 535-544. 